\title{
Gestão de Reclamações: Um Estudo de Caso no Instituto Nacional de Seguro Social
}

Mary Rosanne Bezerra Siqueira ${ }^{1}$; Joelma Martins dos Santos ${ }^{2}$; Arcanjo Ferreira de Souza Neto ${ }^{3}$

Resumo: O objetivo deste artigo é verificar como o Instituto Nacional do Seguro Social - INSS gerencia as informações da Gestão de reclamações, no município de Petrolina-PE.Foram feitas buscas com o objetivo de investigar se o órgão (nesse caso o INSS) possui técnicas específicas na sua gestão de reclamações, pois quando se trata de um ente púbico, em especial INSS, esse processo é reconhecido pela necessidade de uma relação coerente e eficiente com a sociedade, com a finalidade de proporcionar o compromisso do serviço prestado ao usuário. Para esse fim foi realizada a pesquisa bibliográfica juntamente com a pesquisa de campo, utilizando a ferramenta "entrevista", com os gestores do INSS. E o resultado comprovado foi de que não havia uma habilitada gestão de reclamações inerente ao estudo do caso.

Palavras-chave: Gestão de Reclamações, clientes administração pública.

\section{Complaint Management: A Case Study in the National Social Security Institute}

\begin{abstract}
The purpose of this article is to see how the National Social Security Institute - INSS manages information of complaints management in Petrolina municipality.They were made searches in order to investigate whether the body (in this case the INSS) has specific techniques in its claims management because when it is a pubic entity, especially INSS, this process is recognized by the need for a coherent relationship and efficient with society, with the purpose of providing the commitment of service to the user service. To this end it was carried out bibliographic research with field research, using the "interview " tool, with the managers of the INSS . And the result was proven that there was a qualified claims management inherent in the study of the case.
\end{abstract}

Keywords: Complaints , customers Public Administration Management

\section{Introdução}

Na administração pública, em especial no âmbito da oferta dos serviços, é essencial posicionar o usuário no centro dos processos do negócio, pois as ações dos entes governamentais têm impacto na satisfação da população. Sob esse prisma, a gestão da reclamação deve ser adotada como atividade intrínseca das rotinas operacionais, gerando informações estratégicas que servirão de apoio à tomada de decisão para melhorar a qualidade dos serviços prestados.

\footnotetext{
1,2 Economia - FACAPE. Autor correspondente. E-mail: marymarcelinhoc@ bol.com.br;

${ }^{3}$ Graduação em Administração pela Universidade Federal de Pernambuco - UFPE. Licenciatura em Ciências - Habilitação Matemática pelas Faculdades Integradas da Vitória de Santo Antão e Mestrado em Administração pela Universidade Federal de Pernambuco. Atualmente é Professor Assistente da Universidade Federal do Vale do São Francisco - UNIVASF e doutorando em Antropologia Social e Cultural na Universidade de Coimbra - PT.
} 
Assim, a qualidade na prestação do serviço surge no setor público como uma forma de garantir um atendimento que venha atender as necessidades do usuário, permitindo que se cumpra o princípio da eficiência, inserido na Constituição Federal. Porque é no momento da prestação do serviço que o governo é julgado diariamente (CARRIJO et al., 2011).

Dessa forma, a demanda por esse estudo surgiu mediante ao grande desafio das organizações em utilizar modelos que tenham sido pesquisados e validados por profissionais de $\mathrm{RH}$, e a busca de embasamento teórico-científico para proposição de ferramentas que possam ser aplicadas em gestão de pessoas de forma sistematizada e organizada, disseminando o conhecimento nas organizações e com outros profissionais.

O grande desafio das organizações referente à temática é perceber como a aplicação de uma gestão de reclamações pode contribuir para a melhoria do serviço público. Sendo assim, foi observado como o Instituto Nacional do Seguro Social utiliza as informações das reclamações.

De acordo com Kau et al (2006) a gestão de reclamações contribui a medida que obtém informações sobre a qualidade dos serviços e proporciona agilidade nas respostas aos usuários.

Dessa forma, buscou-se verificar, através de um estudo de caso, as principais dificuldades que o órgão público escolhido possui no processo de reclamações. Espera-se com esse estudo melhorar a gestão de reclamações. Diante desse fato cabe questionar: de que forma a Gestão de reclamações pode contribuir para melhoria dos serviços no município de Petrolina- PE?

As buscas foram em caracterizar o setor de gestão de reclamações da instituição escolhida; verificar se a instituição possui indicadores que mensurem a gestão por reclamações; avaliar se a gestão de reclamações tem proporcionado melhorias no serviço da instituição pública.

\section{Gestão de Reclamações}

As empresasdefrontam-se diariamente com um grande desafio: satisfazer os seus clientes. Reclamações são informações extremamente ricas no que concerne a solução dos problemas que devem ser melhorados. O registro da reclamação realizado pelo cliente ajudará a empresa a impor melhorias no bem e/ou serviço prestado ao cliente, outros benefícios oriundos do registro podem ser mencionados tal como a retração de custos e esforços futuros, mas especialmente, a manutenção da satisfação dos usuários.

Como bem menciona Oliver (1980) os clientes avaliam as suas expectativas relativamente ao produto/serviço com o desempenho real deste, existindo um sentimento neutro por parte dos clientes quando o desempenho corresponde ao esperado, um sentimento de satisfação quando o desempenho é superior ao esperadoe, por fim, um sentimento de insatisfação quando o desempenho é inferior ao desejado. 
Conforme destaca Tax e Brown (1998), o objetivo da gestão de reclamações consiste em prestar um suporte necessário capaz de permitir ao clientes expressar as suas reclamações, fornecer um processo e uma solução justa.

Para Johnston e Mehra (2002) o cliente precisa visualizar a forma de proceder o registro da reclamação, assim como os funcionários deveram responder a esta, atendendo a necessidade do cliente.

Ainda, os autores chamam atenção para ações que deveram ser realizadas pelas empresas, tais como: i) focar na redução das causas das reclamações, ao invés da redução do volume, e ii) recolher dados durante o processo para evitar/corrigir os problemas ocorridos.

O processo de gestão de reclamações faz com que a empresa reduza as causas de seus problemas e não tanto o número de reclamações, para isso é necessário que seus colaboradores conheçam a estrutura, os processos e os procedimentos da empresa (CLÁUDIO et al 2014).

Tax e Brown (1998), destacam que a gestão de reclamações deverá simplicar os processos e dar uma resposta rápida e apropriada, ou seja, resolver o problema o mais rápido possível. Em verdade, um funcionário ao receber uma reclamação deverá ser responsável, a partir do momento que a recebe até ser resolvida, buscando a satisfação do cliente. Como ferramenta para solução dos problemas, as empresas precisam inserir práticas que motivem e permitam aos funcionários agirem rapidamente, de forma autónoma e eficaz, em caso de ocorrer uma falha.

Os autores ressaltam que a eficiência na gestão de reclamações só ocorrerá quando os funcionários forem capacitados, estes deveram receber treinamentos com a finalidade de conhecer a estrutura, os processos e os procedimentos da empresa.

$\mathrm{Na}$ administração pública, a gestão de reclamações assume um caráter ainda mais importante, tendo em vista a visão atual de burocracia excessiva e ineficiência. Como bem menciona Bernando (2010), as empresas de um modo geral devem fazer uma gestão adequada das reclamações, pois isso contribui para recuperar os clientes insatisfeitos melhorando a imagem da empresa.

A qualidade dos serviços, em verdade, também pode ser obtida através da gestão de reclamações o que recai em vantagens competitivas. A resposta ao usuário deve ser ágil, com a o advento da tecnologia muitos clientes insatisfeitos acabam recorrendo a internet para expor a insatisfação com o serviço, sendo assim é importante agilidade no feedback.

\section{Relação empresa e cliente}

O aporte teórico existente sobre o tema versa sobre empresas privadas o que não impede de ser utilizado nas empresas públicas e demais entidades, tais como autarquias. Sendo assim, na relação empresa e cliente, há dois fatores que se deve considerar: clientes satisfeitos versos clientes insatisfeitos. 
Essa relação é de suma importância para a empresa. Partindo do pressuposto de que existem vários tipos de clientes e que cada cliente tem um jeito e uma personalidade diferente, por qual razão ou motivo um cliente reclama e outro não de um produto ou serviço (CLÁUDIO et al 2014).

$\mathrm{Na}$ literatura, alguns autores afirmam que aqueles clientes que não reclamam consistem na convicção de que a empresa não vai responder a essa reclamação, não querem enfrentar o indivíduo responsável pela falha, na incerteza sobre os seus direitos e nas obrigações da empresa e, por fim, não querem investir tempo e esforço na reclamação (KOTLER, 2010).

Já aqueles clientes que reclamam, ou seja, os insatisfeitos, esses são em si o ponto chave para uma empresa, pois a sua insatisfação consequentemente vai gerar uma reclamação, e é a partir dessa reclamação que a empresa pode reverter a situação e conseguir a fidelização do cliente.

Ao reclamar os clientes indicam que algo está errado e que esperam que a empresa corrija o problema, mas ao mesmo tempo indicam que querem manter o relacionamento com a empresa. A mesma por fim se tiver uma boa gestão de reclamações de seus clientes, e fornecer a eles uma solução mais justa e rápida possível para o problema, melhorará na qualidade do produto/serviço.

A gestão de reclamação não esta somente na forma pela qual é recebida a reclamação, ela deve ser capaz de processar essa informação, com vista a implementar ações para prevenir o mesmo problema no futuro com o mesmo usuário ou qualquer outro.

A empresa deve explicar ao cliente a falha, mantê-lo informado sobre o processo de resolução da sua reclamação, assim como também deve entrar em contato com este no final do processo a fim de obter feedback por parte do cliente e saber se este se encontra satisfeito coma resolução oferecida (processos de follow-up). Oferecer recompensas também retém clientes insatisfeitos. Destarte é mais vantajoso para a empresa clientes que reclamam do que os que não se expressam diretamente(CLÁUDIO et al 2014).

Tax e Brown (1998), destacam que a reclamação de um determinado cliente resulta na implementação de medidas corretivas, a empresa deverá informar o cliente a respeito da modificação introduzida. O círculo de feedback faz com que os clientes se sintam parte integrante da empresa. Quando se trata de algo que não pode ser corrigido, a organização deverá simplesmente explicar ao cliente a razão de tal impossibilidade.

Estes resultados que retornarão ao cliente, permitirão que os procedimentos de trabalho sejam analisados e corrigidos. Nem sempre este retorno do processo é informado ao cliente. Sendo ou não introduzidas as modificações, é de muita valia o contato com o consumidor, para que o mesmo sinta-se satisfeito e note que sua reclamação original causou no mínimo, novos questionamentos sobre os serviços ou produtos da empresa em questão.

\section{Metodologia}


Este trabalhotrata-se de um estudo de caso, o qual identificou os principais entraves que o órgão público escolhido possui no processo da Gestão de reclamações. Partiu-se de uma pesquisa qualitativa, que tem como objetivo melhorar a visão e a compreensão do contexto do problema. A técnica de coleta de dados constitui-se de entrevistas estruradas.

Ainda, de acordo com Gil (1996) uma pesquisa descritiva visa descrever, as características de determinadafenômeno ou o estabelecimento de relações entre variáveis. A forma mais comum de apresentação é o levantamento em geral realizado mediante questionário ou observação sistemática que oferecem uma descrição da situação no momento da pesquisa.

Este estudo é uma pesquisa aplicada por ter finalidade prática, pois busca embasamento para proposição de ferramentas que possam ser aplicadas através da gestão de reclamações de forma sistematizada e organizada.

\section{Análise de Dados}

Para compreensão da gestão de reclamações aplicada em um recorte especifico dentro desse universo maior aludido, considerou-se o objeto desse estudocomo categoria de analise, ou seja, a gestão de reclamações no Instituto Nacional do Seguro Social - INSS. Nesse sentido, cabe destacar a formação e objetivo do INSS, para melhor compeensão desse estudo.

Na década de 90 foi criado através do Decreto n 9935 o INSS mediante fusão do Instituto de Administração Financeira da Previdência e Assistência Social - IAPAS e o Instituto Nacional de Previdência Social - INPS como autarquia vinculada ao Ministério da Previdência e Assistência Social -MPAS.

O INSS é uma autarquia do governo federal vinculada ao Ministerio da Precidência Social, considerado o caixa da previdência social e recebe a contribuição obrigatória dos trabalhadores com carteira registrada e contribuição voluntária de empregados domésticos, trabalhadores avulsos, autônomos, contribuintes individuais, segurados especiais, segurados facultativos, entre outros, exceto servidores públicos (MINISTÉRIO DO TRABALHO E DA PREVIDÊNICA SOICAL, 2016).

Tem por finalidade garantir a subsistência do Trabalhador que, por algum motivo, está impossibilitado de realizar suas funções, a receita do INSS é formada a partir do montante que é repassado, o qual é pago pelas empresas. Normalmente, a contribuição é obrigatória e deduzida diretamente do salário dos trabalhadores (CAIXA ECONÔMICA FEDERAL, 2016).

São beneficiários desse sistema indivíduos que recebem a proteção previdenciária, sendo pessoas físicas, onde a previdência social resguardará sua condição econômica, para tanto os beneficiários da Previdência social são os segurados e seus dependentes, conforme expressa a a Lei 8.213/91, em seu artigo 10, conforme destaca Torres (2016): 
Os beneficiários do Regime Geral de Previdência Social classificam-se como segurados e dependentes, nos termos das Seções I e II deste capítulo." "Os segurados são, ao mesmo tempo, beneficiários da proteção previdenciária e contribuintes da previdência social, conforme o disposto nos arts. 12 e 14 da Lei 8.213/91 e nos arts. 11 e 13 da lei 8.213/91. A proteção da Previdência para os segurados decorre de ato próprio, pelo exercício da atividade laborativa remunerada para os segurados obrigatórios, e pelo recolhimento das contribuições para os segurados facultativos. Por essa razão é que se diz que são beneficiários diretos da Previdência social. Os dependentes, por sua vez, não são obrigados a contribuir para a previdência social. São apenas beneficiários dela.Diz-se que são beneficiários indiretos justamente por isso, porque a proteção não decorre de ato próprio, mas da qualidade de segurado daqueles de quem dependem economicamente (grifos nossos).

Portanto, por ser um ente administrativo autônomo prestador de serviços previdenciários que procura preservar a integridade da qualidade do atendimento aos seus contribuintes, ou seja, tem por finalidade investir no atendimento aos usuários e ser eficiente junto aos seus beneficiários.

A fim de atender o objetivo do estudo, e após tecer breves comentários sobre a formação do INSS, a pesquisa foi realizada da seguinte forma: entrevista com o gestor executivo da unidade do INSS de Petrolina - PE, e dois funcionários que respondem pela unidade, os quais estão alocados em funções correlatas a gestão de reclamações.

Por ser tratar de uma unidade do INSS, e por serem esses funcionários que estão ligados direta e indiretamente a gestão de reclamações, os mesmos foram então escolhidos para entrevista, sendo que os demais possuem outras atribuições. Todos são do sexo masculino com mais de cinco anos, com faixa etária que varia entre 35 e 55 anos, sendo que $90 \%$ deles com experiência de mais de cinco ano na função.

Nas unidades do INSS, os cargos são compostos por profissionais da área fim e da área meio (Técnicos e Analistas do Seguro Socical, Psicólogos, Médicos, Técnicos de TI, Assistentes Sociais e etc), para tanto o objeto de nossa pesquisa envolveu apenas os gestores da unidade do INSS, os quais foram entrevistados e discorreram sobre a gestão de reclamações. Cabe ressltar que não há discrepância significativa entre as respostas dos entrevistados, por isso optou-se em sincronizar as respostas devido a sua similitude. Quando não foi possivel as respostas foram dispostas de acordo com os entrevistados 1,2 e 3 .

Os entrevistados ao responderem a questão: o que o senhor entende por gestão das reclamações?

Os entrevistados acreditam "ser a forma de se administrar as reclamações do usuário, a compreensão das fases de recepção até a conclusão". A fim de complementar o conceito tratado pelos entrevistados, estes atribuíram "características ao sistema, tais como aquelas gerenciam as queixas do segurado, de forma a visualizar a percepção dos segurados em relação ao INSS". 
O conceito explanado pelos entrevistados condiz com a percepção tratada na literatura visto que as reclamações possuem, também uma concepção maior, principalmente quando condiz com o tratamento da reclamação.

Em relação ao tratamento dado a melhoria do serviço, os entrevistados foram questionados da seguinte forma: quando o usuário realiza uma reclamação no INSS, como isso irá contribuir para melhoria do serviço, como o senhor avalia essa questão?

Os entrevistados de um modo geral acreditam que o tratamento dado deverá ser da seguinte forma:

Uma reclamação permite a reavaliação das estruturas de atendimento, sistema, permitindo o crescimento e melhoria do órgão. Contribui na medida em que erros de procedimentos são identificados e corrigidos, bem como se identifica a necessidade de capacitações em determinadas áreas.

Em relação ao usuário do serviço prestado pela unidade do INSS, os gestores foram então arguidos: O usuário tem liberdade de externar sua opinião sobre o serviço, há a possibilidade, também,do anonimato.

De acordo com Entrevistado 1 e 2, o usuário terá o anonimato preservado "juntamente aos canais da ouvidoria, permitindo assim que o usuário expresse sua opinião sobre o serviço".

Para o entrevistado 3 - "sendo possivel verificar a insatisfação desse usuário, que ao ter que se expor pode acabar não opinando, por receio de não ser atendido da melhor forma possivel nas próximas vezes que necessitar do serviço".

Quando questionados sobre as formas disponíveis para que o usurário possa realizar a reclamação.

Os mesmos demonstraram ter canais que facilitem a reclamação, tais como ouvidoria: Entrevistados - "central 135 (telefone), internet e presencialmente na agência, ou pelo site mpts.gov.br".

Com relação aos funcionários, no que concerne ao atendimento, a reclamação do usuário é repassada aos funcionários de que forma? Como o senhor trabalha essas questões dentro do INSS?

Entrevistado 1 - As reclamações são tratadas pelo gestor da agência, que sempre escuta o servidor. Nesse sentido as informações referente as reclamações são tratadas da seguinte forma: primeiramente o servidor é consultado sobre a veracidade dos fatos, depois é questionado se possui alguma limitação interna ou externa que o atrapalha.

Entrevistado 2 - Quando o problema está relacionado às condições de trabalho, tal como a falta de conhecimento, designamos outro servidor para acompanha-lo e dessa forma capacitá-lo.

Entrevistado 3 - Sendo um o problema relacionado ao comportamento do servidor, esse responde administrativamente considerando as disposições do código de ética d servidor e da lei dos servidores públicos federais (lei 8.112/90). 
Cada um dos entrevistados abordou de forma diferenciada a questão de acordo com o seu entendimento, percebe-se que não há um estimulo ao funcionário em tratar a reclamação, embora haja condições de resolução.

Com relação aos serviços ofertados pelo INSS, há treinamento dos funcionários nesse sentido para melhor atender os usuários.

Entrevistados - "Há cursos de capacitação para os funcionários. Entretanto, no momento, a instituição não tem ofertado cursos que viabilizem o treinamento externo e/ou interno dos funcionários",

Os entrevistados ao serem questionados sobre a frequência com que a unidade realiza reuniões formais com os funcionários para discutir, especificamente, como lidar com as reclamações dos usuários, esses responderam que:

Entrevistados - "Não existem reuniões para tratar especificamente das reclamações, os assuntos são tratados na reunião mensal de avaliação".

Portanto, se percebe que as reclamações são tratadas em reuniões nas quais são discutidos assuntos correlatos. Não há prioridade em se tratra a gestão de reclamações, esses são abordados em reuniões gerais o que não torna fundamental para a entidade tratar da satifação e insatisfação do usuário, o objetivo é ofertar o serviço sendo o usuário secundário nessa relação.

Em relação as reclamações dos usuários, os funcionários podem externar suas opiniões, como realizam suas jusiticativas?

Para os entrevistado 1 - "os funcionários sempre são ouvidos, pois se constrói o histórico da reclamação, os dois lados da situação, assim como algumas vezes os funcionários buscam justificar as reclamações".

Entrevistado 2 - "Normalmente as reclamações dizem respeito ao atendimento. Entretanto, não podemos generalizar, pois muitas vezes as reclamações não procedem".

Ainda, de acordo com os entrevistado 3

Quando essas reclamações procedem, buscamos resolvermos o problema ocorrido. Em casos extremos onde não há solução, explicaremos ao demandante. Sendo que estipulamos prazos ao usuário, já previamente determinados por nosso sistema de atendimento.

Dentre as habilidades a serem desenvolvidas para melhor atender o usuário, pós reclamações, quais são na sua concepação?

Entrevistados "As habilidades que são desenvolvidas são a cordialidade e a urbanidade".

Existe alguém responsável, especificadamente, para acompanhar as reclamações, se foi ou não solucionada, há efetivamente alguém destinado para essa atividade?

$\mathrm{Na}$ concepção dos entrevistados, quem acompanha as reclamações é "o gestor da unidade através do sistema da ouvidoria". 
Id on Line Revista Multidisciplinar e de Psicologia

Id on Line Multidisciplinary and Psychology Journal

Com relação ao grau de flexibilidade que os funcionários dispõem para poder alterar o serviço e lidar com essas reclamações?

Entrevistado 1 - "Existem metas de que as reclamações sejam respondidas em ate 20 dias".

Entrevistado 2 - "Os servidores podem opinar e são ouvidos, contudo quem define os serviços de cada servidor é o gestor da unidade que avalia a necessidade organizacional da administração".

De acordo com o Entrevistado 3

O usuário sempre recebe um retorno sobre suas reclamações, no prazo estabelecido e mediante a sua procura aos nossos serviços. Existe um sistema para armazenarmos as reclamações e realizarmos o tratamento dos dados. As informações são utilizadas frequentemente para o acompanhamento das reclamações para determinada unidade ou determinado servidor, servindo de histórico local. As informações são acessadas por gestores ligados as áreas de atendimento. Servem para melhorar o serviço na medida em que apontam áreas/ temas/ serviços que precisam de melhor atenção e capacitação.

Dessa forma pode-se verificar que o banco de dados formado pelas reclamações realizadas pelos usuários, permite avaliar itens como: os serviços de maior ocorrência de reclamações; as causas principais das reclamações dos usuários; o número de reclamações procedentes e reclamações não procedentes.Como meta o INSS objetiva reduzir ao máximo as reclamações, ofertando respostas rápidas aos segurados. Entretanto, não tem por objetivo reduzir as causas das reclamações.

\section{Considerações Finais}

A satisfação do usuário esta, atualmente, relacionada ao fedebeeck, a melhoria na qualidade do atendimento, da resolução das demandas. Isso possibilita a centralidade do gerenciamento de reclamações, o que pode ser considerado um elemento central na relação de avaliação usuário e unidade do INSS. O objetivo deste artigo foi verificar como o Instituto Nacional do Seguro Social INSS gerencia as informações da Gestão de reclamações, no município de Petrolina-PE.

Dessa forma pode-se verificar como as reclamações são tratadas. Após identificar a causa da reclamação e definir a disposição adequada para corrigir o problema que originou a reclamação do usuário. O INSS nãoentra em contato com o usuário para informá-lo sobre a resolução do problema, existe um prazo para que o usuário procure a entidade. Isto é, o usuário do serviço precisa procurar a unidade para buscar a solução a possivel resposta da solução do problema, isso para evitar as fraudes do sistema.

Como o INSS possui metas a serem cumpridas, as informações que estão dispostas no banco de dados refletem, também em indicadores de desempenho, a qual permite monitorar a eficiência do 
processo e são fontes de informação para a melhoramento da qualidade do serviço prestado ao beneficiário.

Portanto, dentre as deficiencias que se pode observar diante da entrevista com o gestor e funionários é que o INSS não tem um gestor ou funcionário específico que monitore a gestão de reclamações, o que fica concentrado no gestor executivo da unidade. O objetivo não é retrair o volume de reclamações, mas desenvolver ferramentas que possam dar suporte ao corpo de funcionários que estão ligados diretamente com o beneficiário do serviço, e que não haja incidência da reclamação.

Dessa forma se percebe que não é objetivo principal da agência minimizar as reclamações, o que não deixa de ser objetivo secundário. Para uma unidade que possui metas, seria importante trazer elementos que pudessem dar uma sustentabilidade maior as informações geradas pelo banco de dados de forma a centralizar tais informações e tratar as reclamações, em vista de sistematizar estratégias que mimetizem tais demandas. O objetivo deveria reduzir as causas que viabilizem as reclamações, entretanto se percebe que o gestor da unidade é o responsável por gerenciar o banco de dados das reclamações, não se destacou um funcionário especifico para esse fim.

Como o INSS é uma autarquia o sistema de informações é utilizado por todas as unidades nacionais, sendo implementado na unidade de Petrolina, mas não há um suporte para as demandas locais dos usuários, são estratégias gerais que são aplicadas. Dessa forma pode-se concluir que a gestão de reclamações não é utilizada da melhor forma possivel.

\section{Referências}

BERNARDO, Ana Catarina Cachado. (2010). Factores explicativos da reclamação em serviços -O papel do controle de informação e do grau de relacionamento. Disponível em: <https://estudogeral.sib.uc.pt/bitstream/10316/13526/1/reclama\%C3\%A7\%C3\%B5es\%20tese\%20wor d.pdf> Acesso em 03 março 2016.

CAIXA ECONÔMICA FEDERAL. Disponível em: <http://www.caixa.gov.br/beneficiostrabalhador/inss/Paginas/default.aspx >. Acesso em: 02 de abril de 2016.

CARRIJO, Carmen Vânia; et al. (2011). Qualidade do atendimento prestado ao cliente-cidadão da secretaria municipal de regulação urbana de Aparecida de Goiânia - um estudo exploratório e propositivo. Disponível em: < http://www.convibra.com.br/upload/paper/adm/adm_3104.pdf> Acesso em: 03 de março de 2016.

CLÁUDIO, Ana Rafaela de Sousa; PEDRON, Cristiane Drebes; GONÇALVES, Paulo Almeida. O Novo Desafio da Gestão de Reclamações: As Redes Sociais. Disponível em: $<$ http://www.anpad.org.br/admin/pdf/2014 EnANPAD MKT864.pdf $>$. Acesso em 01 de abril de 2016.

GIL, Antônio C. Como elaborar projetos de pesquisa. 3. ed. São Paulo: Atlas, 1996. 
Id on Line Revista Multidisciplinar e de Psicologia

Id on Line Multidisciplinary and Psychology Journal

GOMES, E. G. M. Gestão por Resultados e eficiência na Administração Pública: uma análise à luz da experiência de Minas Gerais. São Paulo, 2009.

INSTITUTO NACIONAL DO SEGURO SOCIAL. Disponível em <http://www.mtps.gov.br/> Acesso em: 15 de abril de 2016.

JOHNSTON, R. e MEHRA, S. Best-practice complaint management. Academy of Management Executive, 2002.

KOTLER, Philip. Administração de Marketing. 10ª ed, São Paulo: Prentice Hall, 2000.

Regras do INSS e da Previdência Social e o que fazer para a aposentadoria. Disponível em: 〈http://previdencia.social/o-que-e-o-inss-para-que-serve/>. Acesso em 20 de abril de 2016.

SARAIVA, E.; ALVES. P. V. Avaliação de desempenho da gestão pública municipal. Junho, 2008.

TAX, S.S. e BROWN, S.W. (1998). Recovering and Learning from Service Failure. Sloan Management Review.

TORRES, Fabio Camacho Dell'Amore. Os segurados da Previdência Social. Disponível em: http://www.ambito-juridico.com.br/site/index.php?n link=revista artigos leitura\&artigo id=11213

Como citar este artigo (Formato ABNT):

SIQUEIRA, M.R.B.; SANTOS, J.M.; SOUZA NETO, A.F. Gestão de Reclamações: Um Estudo de Caso no Instituto Ncional de Seguro Social. Id on Line Revista Multidisciplinar e de Psicologia, Julho de 2016, vol.,10 n.30, Supl 1. p. 225-235. ISSN 1981-1179.

Recebido: $28 / 05 / 2016$

Aceito: 31/05/2016 